\title{
Tendências de uso de pronomes locativos na língua portuguesa dos séculos XVIII ao XIX
}

\author{
Mariangela Rios de Oliveira ${ }^{1}$ \\ Universidade Federal Fluminense \\ Monique Petin Kale dos Santos ${ }^{2}$ \\ Universidade Federal do Rio de Janeiro
}

Resumo: Análise de pronomes locativos em textos da língua portuguesa dos séculos XVIII ao XX. Com base na linguística centrada no uso (TRAUGOTT; TROUSDALE, 2013; BYBEE, 2010), entre outros, se investigam as tendências de uso dos locativos aí, ali, aqui, cá e lá, bem como dos seus aglutinados daí, dali e daqui, com base em quatro fatores - sintático, semântico, textual e cognitivo. Esses fatores apontam mudança linguística, com a alteração da ordenação dos locativos, de pré para pós-verbal ao longo dos séculos pesquisados, e, de outra parte, revelam estabilidade de uso também, ligada ao contexto discursivo de opinião das fontes pesquisadas.

Palavras-chave: Pronomes locativos. Funcionalismo. Língua Portuguesa. Ordenação. Linguística Histórica.

\section{Introdução}

Neste artigo, voltamo-nos para o levantamento e a análise interpretativa dos padrões de uso dos pronomes locativos aí, aqui, ali, lá e cá, bem como dos seus aglutinados daqui, dali e daí, em textos portugueses do gênero opinativo ${ }^{3}$, produzidos nos séculos XVIII, XIX e XX. Como motivações para a seleção de nossos objetos de pesquisa, citamos: a) a busca de regularidades na investigação de uma categoria marcada por heterogeneidade, como a dos advérbios, uma classe de palavras caracterizada por hibridismo e dificuldade de classificação, como já assinalaram Câmara Jr (1998), Ilari et alii (1991), Neves (2000), Castilho (2010), entre outros estudiosos do português; b) o interesse em pesquisar os cinco pronomes mais frequentes em uso na língua, no conjunto dos locativos; c) em termos sincrônicos, a relação

\footnotetext{
${ }^{1}$ Professora Associada da Universidade Federal Fluminense (UFF), docente permanente do Programa de PósGraduação em Estudos de Linguagem. Pesquisadora IC do CNPq; coordenadora do GT Descrição do Português, da ANPOLL; editora da Gragoatá e coordenadora nacional do Grupo de Estudos Discurso \& Gramática. E-mail: mariangelariosdeoliveira@gmail.com.

${ }^{2}$ Mestra em Letras pela Universidade Federal Fluminense (UFF) e doutoranda em Linguística pela UFRJ. Email: moniquepks@ig.com.br.

${ }^{3}$ Usamos esse rótulo para nos referirmos genericamente aos textos articulados em torno da expressão de pontos de vista, de caráter eminentemente dissertativo.
} 


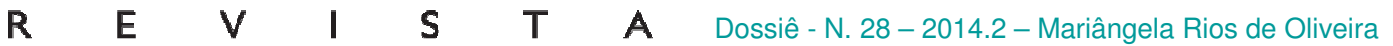 Monique Petin Kale dos Santos}

que consideramos existir entre emprego gramatical e articulação textual-discursiva, na vinculação entre esses dois domínios para a configuração de padrões de uso; d) em termos diacrônicos, a captura de trajetórias de mudança do português ao longo dos séculos pesquisados.

Fundamentados na linguística centrada no uso, nos termos de Bybee (2010), Traugott (2012), Traugott e Trousdale (2013), entre outros, consideramos que estrutura linguística, contexto sociopragmático e aspectos cognitivos atuam em conjunto, em maior ou menor grau, para a convencionalização da gramática. Assim orientados, partimos neste artigo das seguintes hipóteses: i) conforme Martelotta $(2012,2006)$, do século XVIII para o XIX ocorre mudança na ordenação de advérbios do português, visto que, no começo do século XVIII, tais elementos tendiam à posição pré-verbal, diferentemente do que é a ordenação mais sistemática no português contemporâneo, de tipo pós-verbal; ii) de acordo com as sincronias analisadas, e em conformidade com o declarado em i), assumimos que os pronomes locativos prototípicos tendem à posição pré-verbal no século XVIII, enquanto nas sincronias posteriores a maioria destes itens se localiza posteriormente ao verbo; iii) os padrões de uso dos locativos caracterizam-se também por aspectos discursivos específicos, relacionados ao gênero opinativo, notadamente os relativos à semântica, à foricidade e à cognição; iv) devido às características do gênero opinativo, assumimos que essa circunstância discursiva influencia o uso dos locativos com sentidos menos prototípicos, deflagrando, assim, o processo de gramaticalização, segundo Martelotta $(2012,2011)$, pela perda da noção espacial dêitica, pelo distanciamento físico em relação ao falante e pela incorporação de traços de outras categorias, como as dos conectores.

Para dar conta da testagem das hipóteses referidas, selecionamos seis textos de opinião - dois de cada século pesquisado, controlando em cada material o número de caracteres ou de páginas, de modo a garantir a comparabilidade das fontes. Os padrões de uso pesquisados contemplam quatro fatores: a) sintático, relativo à ordenação do locativo face ao elemento verbal na cláusula; b) semântico, atinente ao sentido expresso pelo locativo; c) textual, concernente ao tipo de foricidade instanciada e d) cognitivo, referente ao frame que o locativo compõe na cláusula.

Nosso objetivo, pois, é apontar as tendências de variabilidade, de mudança e de estabilidade detectadas no uso dos pronomes pesquisados ao longo dos três séculos que cobrimos, com base nos quatro fatores citados. 


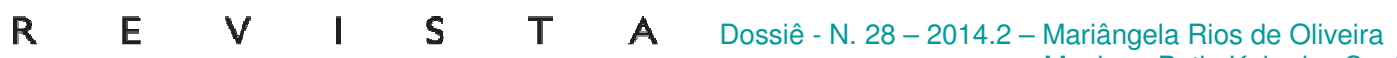

Este artigo se divide em três partes fundamentais. Na primeira, apresentamos os pressupostos teóricos que nos orientam e a metodologia usada na pesquisa. Na segunda parte, descrevemos e analisamos, com base em critérios qualitativos e quantitativos, as tendências de uso dos locativos, a partir dos quatro fatores referidos anteriormente. Na terceira seção, sintetizamos as tendências de uso detectadas, com comentários gerais acerca deste resultado no contexto da pesquisa sobre advérbios do português e da abordagem construcional da gramática, viés mais recente e promissor de investigação da língua em uso.

\section{Fundamentos teórico-metodológicos}

Para investigar a classe pouco homogênea dos advérbios, como destaca Martelotta (2012), em sua rica e abrangente revisão dessa categoria, fundamentamos nossa análise numa perspectiva teórica que analisa os objetos linguísticos de modo holístico e contingencial. Nesse sentido, assumimos os pressupostos da linguística centrada no uso, tais como apresentados em Traugott e Trousdale (2013) e em Bybee (2010), e, no Brasil, apresentados por Martelotta e Alonso (2012) e Martelotta (2011), entre outros.

Nessa vertente teórica, são levadas em conta propriedades de três eixos distintos, dado que o uso linguístico é considerado como resultante da combinação, em maior ou menor escala, de propriedades desses três eixos. Assim, o que falamos ou escrevemos é produto de: a) pressões da própria estrutura linguística, da convenção gramatical; b) motivações sóciohistóricas, do contexto pragmático-discursivo em que se realizam as interações; c) operações cognitivas, enquanto mecanismos gerais inerentes aos seres humanos, como categorização, encadeamento, metaforização, entre outros.

De acordo com tal concepção, usos como os destacados nos fragmentos a seguir devem ser considerados a partir de diversas perspectivas:

(1) Os primeiros românticos principiam a sua atividade na Revista Niterói (1836), consolidam com a Minerva Brasiliense (1843-1844), despedem-se na Guanabara (1849-1855). Daí por diante continuam a produzir, mas perdem terreno como grupo (Formação da Literatura Brasileira, p. 47).

(2) Mefistófeles, voltairiano, e setecentista, sabe que ela é o único recurso do homem, mas Fausto sente que êste só funciona realmente ao compasso dos profundos ritmos vitais. Daí uma dialética da vida e do pensamento, que o neoclassicismo atenuou ao postular a equivalência dos dois têrmos. (Formação da Literatura Brasileira, p. 32) 


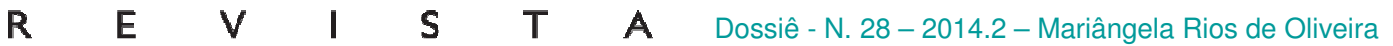 Monique Petin Kale dos Santos}

Para a descrição e análise de daí em (1) e (2), há que se levar em conta a sequência textual em que o locativo se encontra - narrativa em (1) e expositivo-dissertativa em (2), bem como a distinta foricidade desse elemento em cada exemplo e a formação da unidade daqui por diante, em que o locativo se situa em (1), entre outros fatores. Trata-se, portanto, de compreender o uso como contingenciado por uma série de motivações de ordens distintas.

Em conformidade com tal abordagem, na descrição e análise das tendências de uso de pronomes locativos partimos de quatro fatores pelos quais se divide a próxima seção, que contemplam os três eixos referidos anteriormente. Esses fatores são selecionados, entre outros, por sua natureza diversa e pelos resultados significativos que apresentam, seja em termos de mudança, de variabilidade ou de estabilidade detectados nas três sincronias pesquisadas. Tais resultados vão ao encontro de outros, oriundos de pesquisas que temos desenvolvido no contexto de nossa comunidade acadêmica ${ }^{4}$, como os apresentados em Oliveira e Teixeira (2012), Oliveira e Barcellos (2012; 2011), Oliveira e Rocha (2011), Oliveira e Santos (2011), entre outros. Nesses trabalhos, em que pese a diversidade e heterogeneidade no uso dos locativos e nos gêneros discursivos pesquisados, são detectadas tendências de uso, considerados padrões mais regulares que podem ser considerados os não marcados, os modos regulares de expressão dessa categoria. Dentre as tendências verificadas, temos a ordenação pós-verbal para os locativos em seu efetivo uso adverbial e o uso de aqui e ali, o que disponibiliza aí e lá para o cumprimento de outras funções mais gramaticais, como a conexão e a cliticização, por exemplo.

Assim orientados, selecionamos como fontes empíricas textos escritos do gênero opinativo, conforme referido em Marcuschi (2002) e Travaglia (1997). Trata-se de um grupo de fontes que se caracteriza por linguagem mais cuidada, principalmente no século XVIII, que se volta para expressão de pontos de vista, de conceitos mais abstratos ou lógicos, na busca de adesão dos leitores. Os textos pesquisados foram escritos, geralmente, para a burguesia da sociedade europeia e brasileira ou para membros europeus da elite palaciana dos séculos XVIII ao XX. Assim, as obras refletem, de certa forma, pelo uso da linguagem formal, a estrutura organizacional do momento histórico em que são produzidas. Os autores pesquisados dissertam, entre outros assuntos, sobre a sociedade, os sentimentos humanos, a educação e as diversas formas de arte.

\footnotetext{
${ }^{4}$ Grupo de pesquisa dos autores, cadastrado no CNPq.
} 


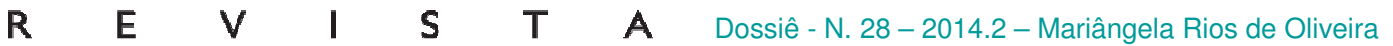 Monique Petin Kale dos Santos}

Em termos metodológicos, delimitamos a quantidade de caracteres ou páginas de cada fonte pesquisada. Assim, obtivemos, em média, de 55.000 caracteres ou em torno de 80 páginas por obra. Consultamos as seguintes fontes (duas por século): a) século XVIII: Reflexão sobre as vaidades dos homens, de Matias Aires (1752), e Verdadeiro método de estudar, de Luis Antonio Verney (1746); b) século XIX: Segundo livro de crítica: arte e litteratura portugueza d'hoje: (livros, quadros e palcos), de Luciano Cordeiro (1871), e o conjunto de textos críticos de Machado de Assis, assim distribuídos: IV - Ideias sobre o teatro (1859), A crítica teatral. José de Alencar: Mãe (1860), O ideal crítico (1865), Crítica teatral (1866) e Notícia da atual literatura brasileira: Instinto de nacionalidade (1873); c) século XX: os três primeiros capítulos da Formação da literatura brasileira (momentos decisivos) (1836-1880), $2^{\circ}$ volume, de Antônio Candido, e Nós e a europa: ou as duas razões (1988), de Eduardo Lourenço.

As obras concernentes aos séculos XVIII e XIX foram pesquisadas em sites eletrônicos ${ }^{5}$. Somente as fontes do século XX foram trabalhadas na versão impressa, uma vez que não estavam disponibilizadas em meio digital no período de desenvolvimento da pesquisa.

Para a investigação, levantamos exaustivamente os locativos aí, ali, aqui, cá e lá, bem como os aglutinados daí, dali e daqui, nas partes delimitadas das obras referidas nos três séculos. Com esse procedimento, chegamos à constituição de um corpus geral formado por 328 dados, assim distribuídos: 38 (d)aí, 61 (d)ali, 177 (d)aqui, 8 cá e 44 lá. Na descrição e análise das tendências de uso, consideramos aspectos de ordem quantitativa e qualitativa, partindo da ordenação, como fator estrutural básico, e chegando à abordagem dos aspectos semânticos, fóricos e cognitivos envolvidos no uso dos locativos.

\section{Tendências de uso}

Nesta seção, trazemos e discutimos os resultados da análise empírica do uso de pronomes locativos nas fontes pesquisadas. Em cada subseção, apresentamos o fator contemplado, acompanhado de informes quantitativos, de comentários avaliativos e de

\footnotetext{
${ }^{5}$ Os sites de referência para coleta dos dados foram: http://www.ime.usp.br/ tycho/corpus/, http://www.purl.pt e http://machado.mec.gov.br/index.php 

R E
$\mathrm{S} \quad \mathrm{T}$
A
Dossiê - N. 28 - 2014.2 - Mariângela Rios de Oliveira
Monique Petin Kale dos Santos

exemplificação. $\mathrm{O}$ foco é a detecção de tendências de mudança gramatical, de variabilidade ou de estabilidade nesses usos.

\subsection{Fatores sintáticos}

Para a investigação das tendências de ordenação de nossos objetos de pesquisa, partimos do levantamento das posições desses itens adaptada de Martelotta (2006) e indicada no quadro abaixo, em que: $\mathrm{V}$ é o verbo, ou seja, o escopo do locativo; $\mathrm{X}$ é qualquer constituinte que se localiza entre o verbo e o advérbio, e vice-versa, não são considerados como $\mathrm{X}$ os clíticos, a partícula negativa ou os advérbios que se referem a outro advérbio; Loc é o pronome locativo:

\begin{tabular}{|c|c|c|c|}
\hline \multicolumn{2}{|c|}{ Posições pré-verbais } & \multicolumn{2}{c|}{ Posições pós-verbais } \\
\hline $\mathrm{P} 1$ & $\mathrm{P} 2$ & $\mathrm{P} 3$ & $\mathrm{P} 4$ \\
\hline $\mathrm{Loc}+\mathrm{V}$ & $\mathrm{Loc}+\mathrm{X}+\mathrm{V}$ & $\mathrm{V}+\mathrm{Loc}$ & $\mathrm{V}+\mathrm{X}+\mathrm{Loc}$ \\
\hline
\end{tabular}

Quadro 1: Ordenação do locativo em relação ao verbo na oração

A classificação dos dados pelas quatro posições referidas no Quadro 1 é sumarizada no Gráfico 1, a seguir:

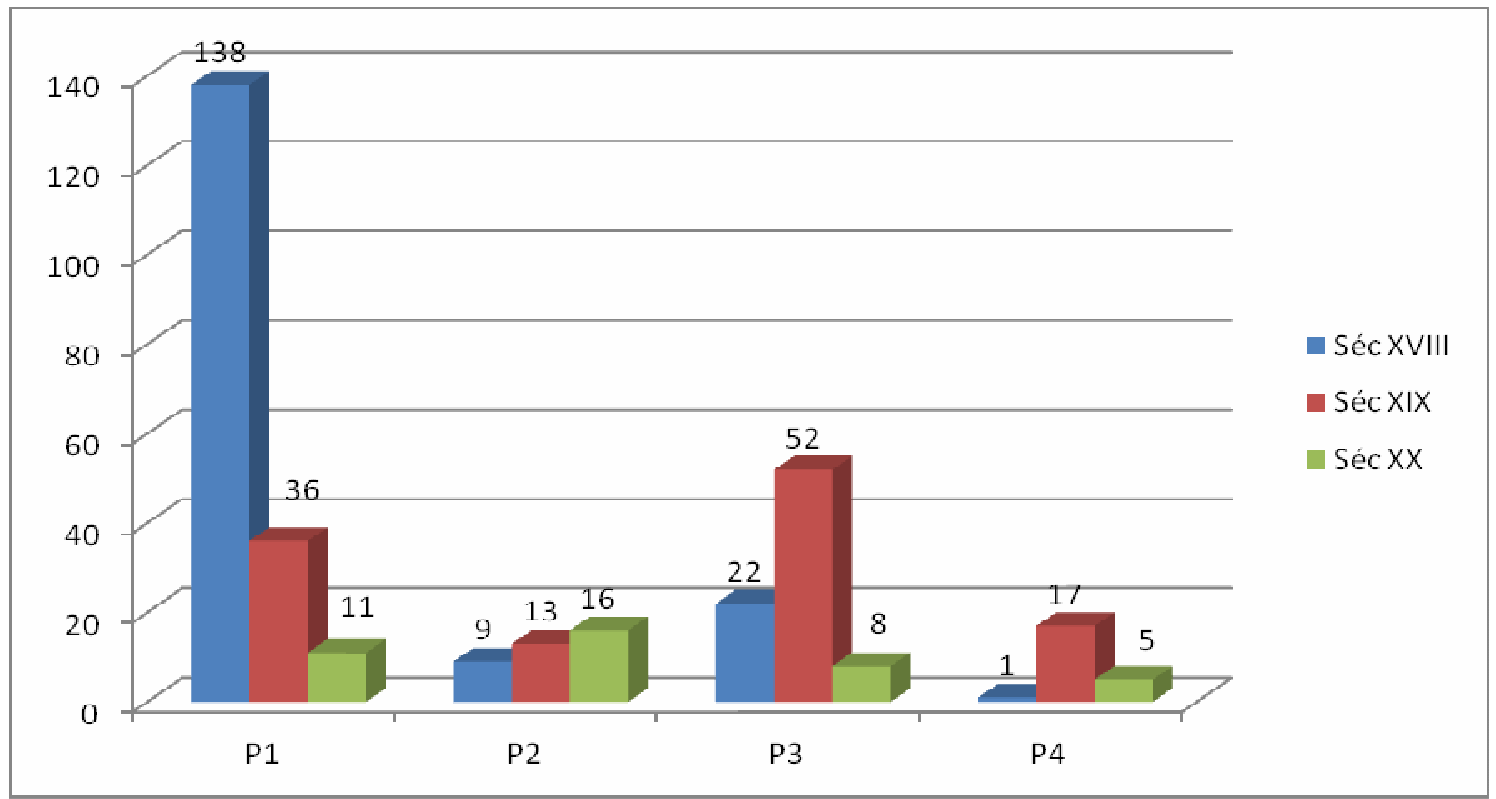

Gráfico 1: Tipos de ordenação de pronomes locativos por século

Como podemos observar, há predominância de locativos imediatamente antes do verbo (P1) no século XVIII, confirmando ser essa a posição não marcada no período referido. Trata- 


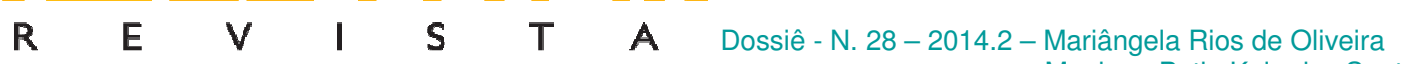

se de resultado que corrobora o que se tem verificado também, em viés histórico, na pesquisa dos locativos em outros gêneros discursivos, como o epistolar (VALADARES, 2012) e o dramatúrgico (BARCELLOS, 2011; OLIVEIRA; BARCELLOS, 2012). Esses resultados confirmam a tese de Martelotta (2006), segundo a qual os locativos, entre outros elementos adverbiais, em sincronias mais antigas da língua portuguesa, tendem a se situar antepostos ao verbo, em ordenação distinta face ao português contemporâneo, quando a tendência sintática passa a ser pós-verbal.

Com relação ao século XVIII, um dado relevante diz respeito à alta frequência do aglutinado daqui encontrados na obra de Matias Aires, conforme ilustramos nos exemplos abaixo. Essa significativa frequência é motivada pela alta ocorrência da expressão daqui vem na obra referida, que perfaz cerca de $70 \%$ dos dados levantados de daqui no Gráfico 1, tal como:

(3) A razão do esforço, regula-se pela razão da vaidade; daqui vem, que em um conflito grande, os ânimos se elevam, e arrebatam; porque algumas vezes é questão do destino de um Império; em lugar que o ardor é lento, quando só se disputa um posto ventajoso. (Reflexão sobre as vaidades dos homens, p. 47).

(4) O merecimento das cousas, não se toma pelo que são, nem pela forma que têm, mas pelo que não são, e pela forma contrária que não têm. Daqui vem que uma acção é louvável, só porque não é repreensível. Aquele meio de não ser, nem uma cousa, nem outra parece que o não há já; ficaram os extremos, e extinguiu-se o meio. (Reflexão sobre as vaidades dos homens, p.142).

Os exemplos (3) e (4) ilustram o uso da expressão daqui vem, encontrada em 46 dados das fontes pesquisadas. Como ressaltamos, essa frequência impactou significativamente o número de locativos encontrados antepostos ao verbo no século XVIII. O par de exemplos mostra a expressão daqui vem funcionando como conectivo textual, pois, ao mesmo tempo em que delimita o fluxo de informações, concorre para o caráter coesivo entre as orações. Essa função conectiva é reforçada tanto pela semântica da preposição $d e$, indicando origem, quanto pela do verbo vir, direcionando o movimento de retomada de algo já citado. Destacamos também que em ambas as sequências predominam as articulações lógicas, o jogo de pontos de vista e as estratégias persuasivas, como destacam Traugott e Dasher (2005), como pressões motivadoras de abstratização de sentidos e de lócus inicial de mudança gramatical.

No decorrer do século XIX, conforme o Gráfico 1, observamos certo equilíbrio na distribuição entre as posições pré e pós-verbal, com frequência maior de P3. Dos 118 dados 


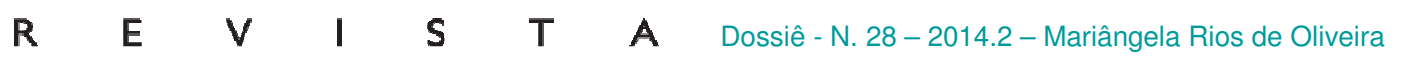

do século XIX, 36 se ordenam em P1, 13 em P2, 52 em P3 e 17 em P4. Nos dados do século $\mathrm{XX}$, constata-se a mesma tendência à variabilidade. Tal resultado evidencia o equilíbrio maior do posicionamento dos locativos em relação ao verbo. Essas observações podem ser respaldadas nos trechos abaixo:

(5) É um retrato ou uma phantasia? Não sei. O que é certo é que não ha ahi ou se ha não se percebe, concepção esthetica. (Segundo livro de crítica: arte e litteratura portugueza d'hoje, p. 19).

(6) 'Um português que é só português não é português'. Sob a fórmula paradoxal, Pessoa, aqui, como em muitos outros domínios, ecoa uma caracteriologia célebre de Oliveira Martins. (Nós e a europa: ou as duas razões, p. 14).

Em (5) e (6), os locativos ahi e aqui, respectivamente, ilustram as posições P3 (pósverbal) e P2 (pré-verbal). Usados com sentido mais abstrato, por conta de fatores de ordem textual-discursiva, tratados na subseção 2.2, os dois fragmentos exemplificam a variabilidade posicional desses constituintes.

\subsection{Fatores semânticos}

Para dar conta do sentido articulado pelos pronomes locativos, observamos sua polissemia através do cline espaço $>$ tempo $>$ texto, fundamentados na teoria localista, como proposta em Batóreo (2000). De acordo com o referido cline, os sentidos mais concretos ou atinentes ao mundo biossocial são recrutados também para a referência temporal e, na sequência, podem chegar à dimensão discursiva, como a articulação de noções lógicas.

Assim considerando, classificamos os dados em dois grupos. O primeiro conjunto se refere à referenciação física e pode ser dividido entre concreto e abstrato. O sentido físico concreto diz respeito a um espaço visível, geograficamente demarcado, com cidade, sala ou país. O sentido físico abstrato é concernente à falta de delimitação concreta, na designação de ambientes mais virtuais, como documentos, cartas ou sonhos. A seguir, ilustramos ambos os tipos de sentido físico classificados:

(7) Assinaladas e postas de parte certas crenças ainda cheias de fé, esse amor ainda santificado, o que resta? Os mercadores entraram no templo e lá foram pendurar as suas alfaias de fancaria. São os jesuítas da arte; (...) (Críticas, p. 40).

(8) Nem pessoa alguma faz caso disto. Sòmente se pratica escrever de próprio punho quando é primeira carta de cerimônia a pessoa grande, ou quando respondo a quem escreve de próprio punho, ou noutros casos assim. Mas, aqui, seria, um caso reservado praticar $o$ contrário.(Verdadeiro método de estudar, p. 42). 
Em (7), o locativo lá, ordenado em P1, retoma o nome concreto templo, numa sequência de base tipológica narrativa. No fragmento (8), o pronome aqui, em sequência expositiva, se refere a um tipo de espaço discursivo-textual, a uma carta, razão pela qual é classificado por nós como físico virtual.

O segundo grupo semântico se relaciona à referência abstrata e, semelhante ao grupo anterior, é formado por dois subconjuntos: temporal e textual. O primeiro expressa ideia de tempo, de acordo com a concepção localista, segundo a qual tempo é derivação de espaço. $\mathrm{O}$ segundo subconjunto, o textual, por sua vez, articula sentidos lógicos, funcionando como estratégia coesiva entre os elementos do discurso. Via de regra, na articulação de sentido abstrato, os locativos integram expressões mais complexas. Os excertos (9) e (10) exemplificam essa taxonomia:

(9) (...) isto é, em ser com antecedência, e ser já, aquilo que certamente há-de vir a ser daqui a pouco: por isso o preso, que se mata, é como um preso que foge; um, e outro, iludiu o castigo, porque este devia consistir na duração, e não na extinção (Reflexão sobre as Vaidades dos Homens, p. 50).

(10) Todos se lembram que Leonel é primo de Leôncio; esse, autor da desonra de Damiana, procura impedir o casamento do primo com Cristina, irmã de Lusbela. Daqui vem a luta entre e Leôncio, que faz uma parte da ação da peça (Críticas, p. 24).

No fragmento (9), o locativo compõe a unidade temporal daqui a pouco, cujo sentido é mais abstrato do que físico. Em (10), em outra unidade complexa, na formação de daqui vem, o locativo passa a assumir maior nível de abstração, uma vez que atua também na conexão textual, imprimindo sentido conclusivo à sequência.

$\mathrm{Na}$ classificação dos fatores semânticos, deparamo-nos com alguns casos de sentido híbrido, a que nomeados de categoria intermediária. Em tais usos, o locativo se encontra em alto grau de polissemia, num tipo de articulação que torna meio impreciso seu sentido. É o que ilustramos a seguir, com o fragmento (11):

(11) O individualismo, destancado o homem da sociedade ao forçá-lo da sociedade sôbre o próprio destino, rompe de certo modo a idéia de integração, de entrosamento - quer dêle próprio com a sociedade em que vive, quer desta com a ordem natural entrevista pelo século XVIII. Daí certo baralhamento de posições, confusão na consciência coletiva e individual, de onde brota o senso de isolamento e uma tendência invencível para os rasgos pessoais, o ímpeto e o próprio desespêro. (Formação da literatura brasileira, p.24). 


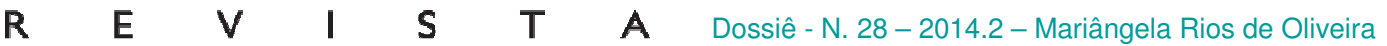 \\ Monique Petin Kale dos Santos}

Em (11), não nos parece clara a possibilidade de interpretação mais definida entre o sentido temporal e o textual do locativo. Assim, julgamos que seja possível a interpretação de daí tanto como em referência à sequência temporal dos fatos quanto como elemento de papel textual, a concorrer para a articulação entre os dois períodos que compõem o fragmento.

No Gráfico 2, apresentamos a classificação dos fatores semânticos de nossos objetos de análise, a partir da taxonomia adotada:

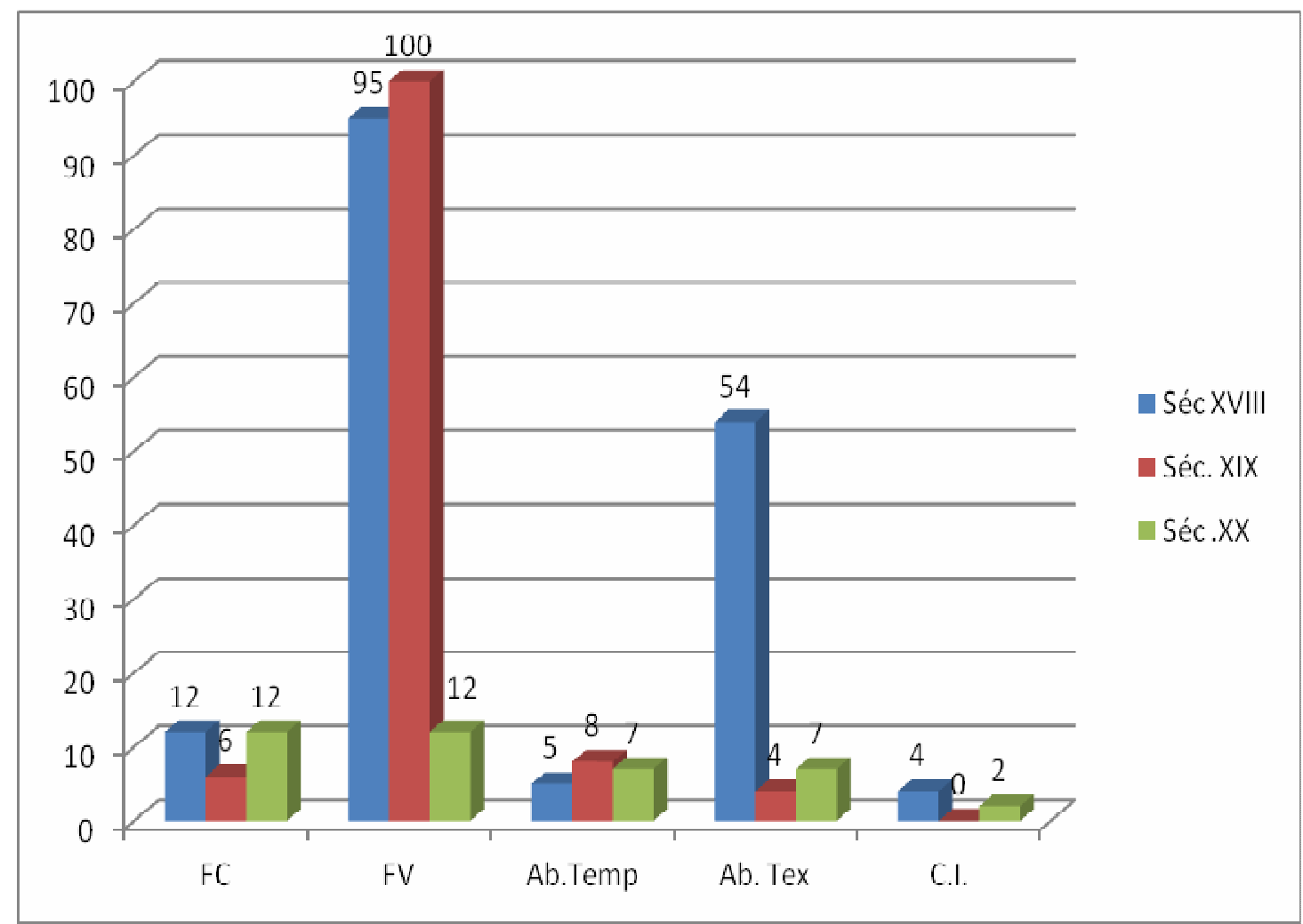

Gráfico 2: Tipos de referenciação de pronomes locativos por século ${ }^{6}$

De acordo com o Gráfico 2, grande parte dos locativos se refere a espaços físicos virtuais, tendência verificada em todos os séculos analisados, conforme o exemplo (8), apresentado nesta seção. Dos 328 dados em análise, 207 codificam esse tipo de referência, o que perfaz quase $70 \%$ do total, demonstrando ser esse o sentido predominante para os locativos no gênero opinativo. $O$ fato de tal tendência ocorrer em todos os três séculos pesquisados é por nós interpretado como um tipo de motivação ligado às condições pragmático-discursivas do gênero de opinião. Dado que nessas fontes é traço constitutivo a

\footnotetext{
${ }^{6}$ As abreviações usadas no Gráfico 2 correspondem as seguintes sentidos: FC - físico concreto; FV - físico virtual; Ab. Temp: abstrato temporal; Ab. Tex: abstrato textual; C.I: conteúdo intermediário.
} 


\section{$\begin{array}{llllllll}\mathbf{R} & \mathbf{E} & \mathbf{V} & \mathbf{I} & \mathbf{S} & \mathbf{T} & \mathbf{A} & \text { Dossiê - N. 28-2014.2-Mariângela Rios de Oliveira }\end{array}$

apresentação e a defesa de pontos de vista, na busca de adesão e convencimento por parte do interlocutor, sentidos (inter) subjetivos e inferências são recorrentes e mesmo esperados. Assim posto, os pronomes locativos atuam como mais um recurso na articulação das estratégias referidas, atuando coesiva e coerentemente nesse ambiente textual. Assumimos que a estabilidade do sentido físico virtual nos três séculos é considerada como traço constitutivo do gênero opinativo, que é identificada, portanto, na trajetória da língua.

O segundo grupo mais frequente é o que articula sentido abstrato textual, o que também pode ser considerado como consequente do gênero opinativo, em que relações lógicas, como conclusão ou consequência, por exemplo, são recorrentes. Destaca-se no Gráfico 2 o sentido textual de daqui, consequente da alta frequência da expressão daqui vem nas fontes do século XVIII, como já referido. Trata-se de usos como:

(12) Cada cousa tem tantas partes por onde se considere, que de qualquer modo que a imaginemos, sempre achamos argumentos, que ou nos persuadem o erro, ou nos confirmam o acerto; daqui vem que há opiniões para tudo, assim como para tudo há exemplos. Aquilo, que nos parece que é sem dúvida, é donde às vezes a há maior. (Reflexão sobre as Vaidades dos homens, p. 114).

No fragmento (12), a expressão daqui vem funciona como elemento conectivo, pois não só promove a progressão textual, mas também retoma alguma informação prévia. Assim posto, detectamos a formação de uma unidade pré-fabricada, nos termos de Erman e Warren (2000), que atua no nível sintático-semântico, como um todo de forma e sentido que estabelece relação conectiva, na articulação de sentido lógico. Trata-se de mudança gramatical, ou gramaticalização, segundo Traugott e Trousdale (2013), em que se fixa e convencionaliza um novo tipo de pareamento de sentido e forma, cujo sentido é distinto da soma dos sentidos de cada subparte (no caso, daqui e vem).

Quanto aos demais tipos de referenciação, físico concreto e abstrato temporal, cada subgrupo chega a cerca de $10 \%$ do total, contingente ainda maior do que o dos casos intermediários.

\subsection{Fatores fóricos}

Nesta subseção, tratamos das relações referenciais que o locativo estabelece com os demais elementos textuais. Tais relações podem ser de natureza endofórica (anafórica ou catafórica) ou exofórica. Segundo Koch (2011), na coesão endofórica, a referenciação é 


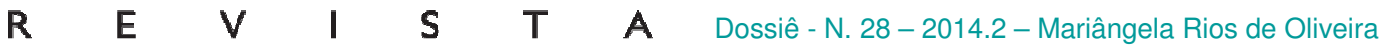 \\ Monique Petin Kale dos Santos}

articulada entre os elementos do próprio texto; na coesão exofórica, a atribuição de referência aponta para situação contextual externa.

Em que pese a falta de consenso acerca da maior distinção ou não entre dêixis e referenciação, como apresentado em Castilho (2010), por exemplo, adotamos na pesquisa dos fatores fóricos envolvidos no uso dos pronomes locativos estudados a proposta de Koch (1990), referida no parágrafo acima. Assim estabelecido, apresentamos, a título de ilustração, os exemplos a seguir, que ilustram relações fóricas dos locativos:

(13) (...), depois dragão, depois beldade, para afinal tornar-se o próvido Vígilio de Colombo, levando-o ao Inferno, para de lá mostrar-lhe eruditamente as idades pré-históricas, (...). (Formação da Literatura Brasileira, p. 72).

(14) A partir daí, de 1850, digamos, as diferentes coroas de Magalhães começam a vacilar e perder prestígio, ante a pura grinalda do cantor d' Os Timbiras: (Formação da Literatura Brasileira, p. 56).

Em (13), o elemento destacado retoma a palavra inferno, mencionada anteriormente. Em (14), o aglutinado daí se refere ao ano de 1850, citado posteriormente. As relações endofóricas (tanto anafóricas quanto catafóricas), exemplificadas em ambos os fragmentos, constituem o tipo mais comum de referenciação dos locativos nas fontes pesquisadas.

Se levarmos em conta de que lidamos com o gênero opinativo nos três séculos pesquisados, é possível relacionar essa tendência, como demonstramos no Gráfico 3, ao gênero referido, uma vez que se trata de textos em que as relações contextuais internas, os movimentos de avanço (anáfora) e expansão (catáfora), são mecanismos importantes para o estabelecimento de relações lógicas e mais abstratas, próprias dessas fontes. De outra parte, pode ser também que essa seja uma tendência mais geral da modalidade escrita, dado que, desprovida dos elementos situacionais próprios da interação face a face, o traço maior dessa modalidade seja a ênfase no apontamento de relações textuais internas, menos ancoradas na situação comunicativa externa.

O gráfico a seguir ilustra a tendência aqui referida: 


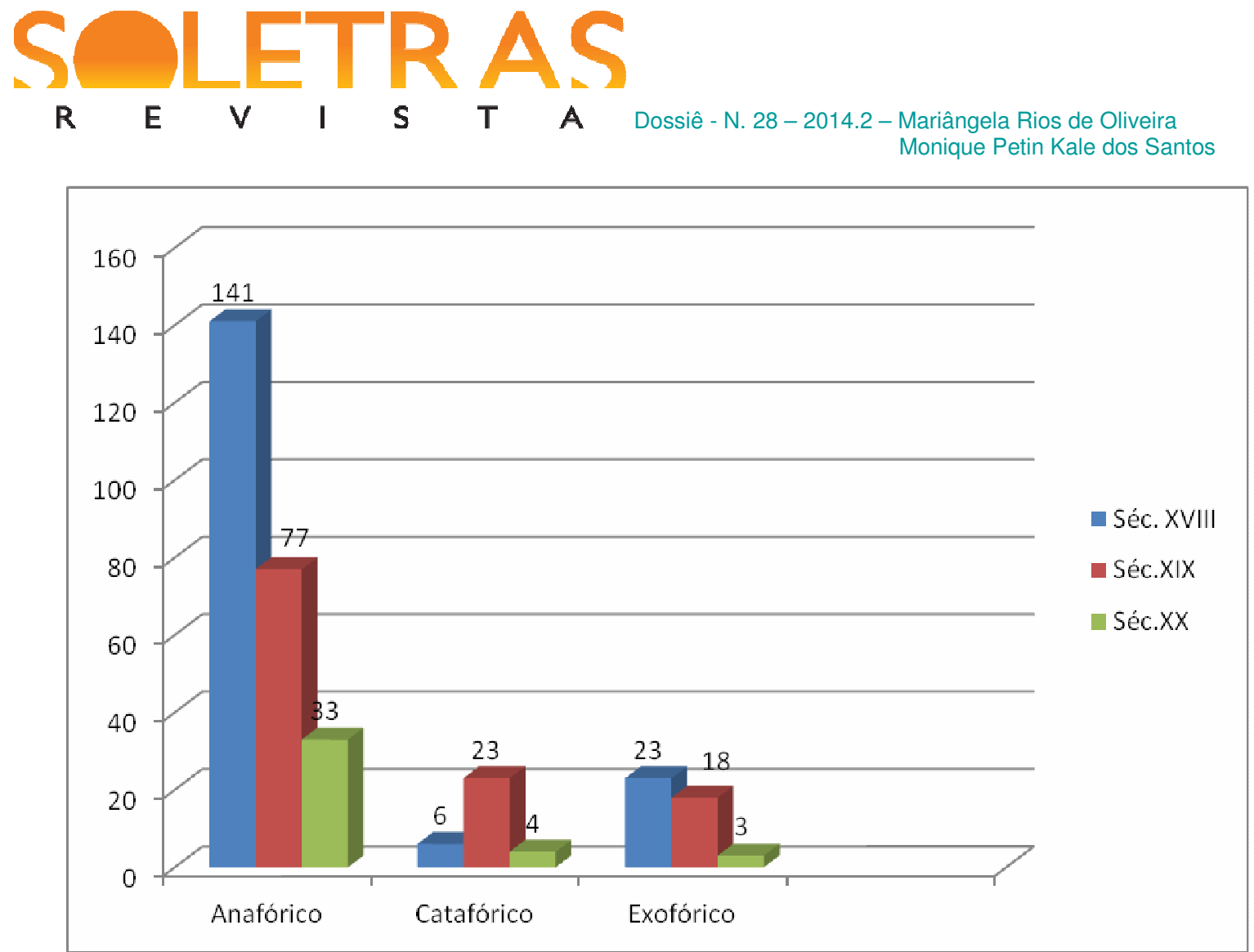

Gráfico 3: Tipos de foricidade de pronomes locativos por século

Como constatado a partir do Gráfico 3, dos 328 dados gerais, 251 (quase 80\%) dizem respeito a relações anafóricas, ficando as demais estratégias circunscritas a poucas ocorrências (44 exofóricas e 33 catafóricas). Nas três sincronias pesquisadas, a tendência se mantém. No século XVIII, a aludida expressão daqui vem concorre para o incremento da referenciação anafórica:

(15) $\mathrm{O}$ ph dos Gregos era um p aspirado com muita força e que alguma coisa declinava para f; e, não havendo em Portugal semelhante pronúncia, é erro introduzir o dito p, quando temos cá o f, que tem o seu próprio soído. Daqui vem que, ainda que Filozofia, Triumfo etc.,, na sua origem tivessem o ph, (...) (Verdadeiro Método de Estudar, p. 57).

Na sequência (15), o uso da expressão daqui vem funciona como conector textual, na composição de uma unidade de sentido e forma altamente vinculada. Para a instauração da função coesiva, o papel anafórico de daqui é fundamental. Dentre os 96 casos do locativo (d)aqui com função anafórica no século XVIII, 46 dados nesse padrão de uso.

No que concerne às demais estratégias, vale destacar que, por serem considerados os pronomes locativos mais leves $^{7}$, em termos semânticos e estruturais, os casos de catáfora têm

\footnotetext{
${ }^{7}$ Termos leves são aqueles considerados menos extensos em forma (monossílabos, por exemplo) e em sentido (pronomes e demais partículas gramaticais).
} 


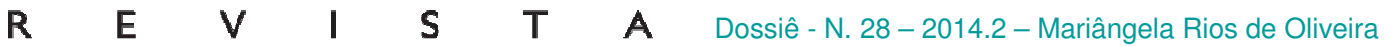 Monique Petin Kale dos Santos}

como motivação, muitas vezes, o preenchimento do sentido espacial perdido. É o que constatamos em:

(16) É isto, este nasce em Paris, ou, o que significa o mesmo, num campo bem limpo da Suécia. Logo Mestres lhe rodeiam o berço; todas as civilizações estão lá na biblioteca paterna (Nós e a Europa: ou as duas razões, p. 139).

No fragmento (16), o esvaziamento semântico de lá é compensado pela informação subsequente, na biblioteca paterna. De acordo com Paiva (2003), a falta ou perda de especificação dos pronomes locativos é compensada pelo uso de estratégias como a ilustrada em (16), em que a expressão espacial preenche o sentido pronominal esvaído, concorrendo para a cataforização.

\subsection{Fatores cognitivos}

O quarto parâmetro analisado, de base cognitiva, aborda o locativo a partir do frame, ou enquadramento cognitivo, do qual participa. Conforme Fillmore (1982, p. 116-117), o significado dos constituintes linguísticos depende do frame no qual estão inseridos, que tem a ver com a situação comunicativa em que se produz a interação. Dessa forma, a interpretação de um determinada palavra, ou de um conjunto delas, necessita do acesso a estruturas de conhecimento que relacionam elementos e entidades atinentes a cenas de experiência humana, considerando-se as bases físicas e culturais dessa experiência.

Para a análise dos fatores cognitivos, verificamos, no âmbito da oração, se a relação entre os participantes (sujeito e objeto), o locativo e o verbo formam ou não um frame de base locativa, isto é, analisamos se a predicação verbal e seus argumentos articulam um tipo de enquadramento no qual o espaço físico, mais concreto, prevalece. Ilustramos o comentário com os seguintes exemplos:

(17) Os vícios lá parece que dependem da fortuna; porque as ilusões que os homens idolatram, não têm igual estimação em toda a parte (Reflexão sobre as vaidades dos homens, p. 77).

(18) (...), realisada pelos artistas que vão á Itália estudar-nos ou com os grandes mestres e pelos que do norte veem viajar ou estabelecer-se aqui (Segundo livro de crítica: arte e litteratura portugueza d'hoje, VIII Um parenthesis - no. 59 - $3^{\circ}$. Parágrafo).

No trecho (17), o locativo lá integra uma oração de frame não-espacial, pois, além de estabelecer relação com o verbo cognitivo parecer, se relaciona com sujeito não-agentivo e não-humano, indicado nesse exemplo pelo sintagma os vícios; trata-se de uma sequência de 

R E
S T
A
Dossiê - N. 28 - 2014.2 - Mariângela Rios de Oliveira
Monique Petin Kale dos Santos

opinião, altamente abstrata. Já em (18), o locativo aqui articula relação espacial, compondo oração que tem sujeito agentivo e humano (os artistas) e predicado verbal em torno de estabelecer, em sentido físico concreto.

No Gráfico 4, sintetizamos o levantamento do frame dos locativos, partindo somente da distinção entre os traços espacial e não-espacial:

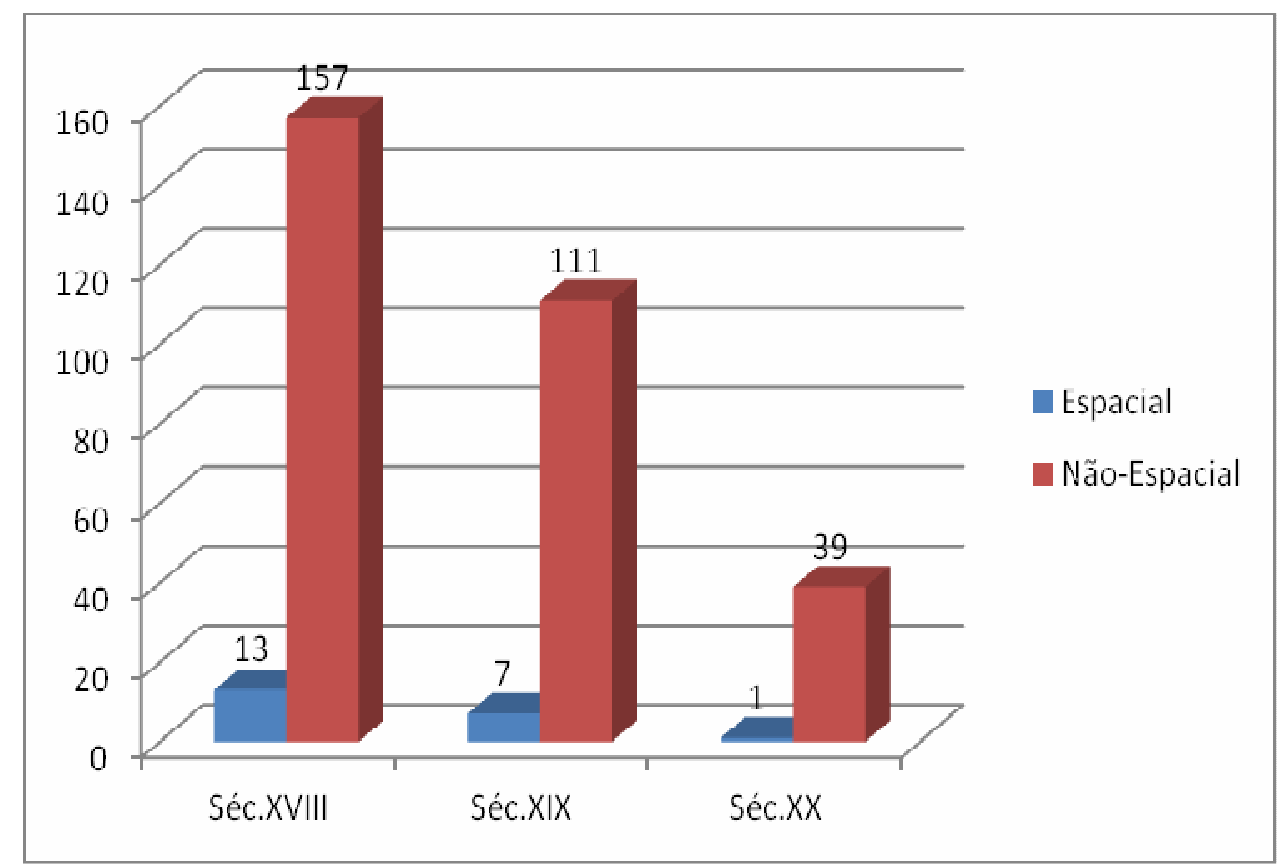

Gráfico 4: Tipos de frame integrados por pronomes locativos por século

Como constatamos pelo Gráfico 4, em praticamente 90\% dos dados (307 de 328 gerais), os locativos pesquisados compõem frame não-espacial. Essa tendência, verificada nas três sincronias pesquisadas, em conformidade com Traugott e Dasher (2005), destaca o papel dos elementos contextuais, na perspectiva da metonimização, bem como a derivação de sentido consequente do relacionamento de tais elementos, no viés da metaforização.

Com base na constatação de que se trata de textos opinativos, a prevalência de frame não-espacial é justificada, uma vez que, para apresentar e defender pontos de vista, é preciso lidar com sentidos mais abstratos, com objetos de discurso mais complexos e mesmo etéreos. Assim posto, consideramos que os fatores cognitivos no uso de pronomes locativos se apresentam como propriedades estáveis desse gênero na trajetória do português, dado que se inserem no enquadramento da expressão de opinião. 


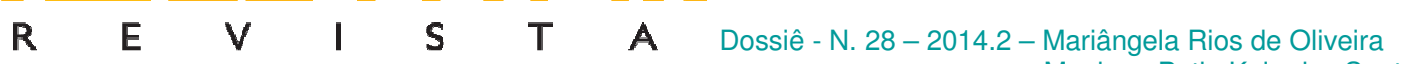

\section{Considerações finais}

Após apresentação e comentário dos quatro fatores envolvidos no uso dos pronomes locativos aí, aqui, ali, lá e cá, bem como dos seus aglutinados daqui, dali e daí, em seis fontes de três sincronias do português, do século XVIII ao XX, podemos apontar algumas tendências de uso, tanto no sentido de detecção de certa trajetória de mudança quanto de marcas de estabilidade. Os resultados permitem ainda vincular mais efetivamente o nível gramatical e o discursivo-pragmático, como instâncias que se combinam e mutuamente motivam a produção textual, como proposto em Oliveira (2012), na perspectiva da linguística centrada no uso (TRAUGOTT e TROUSDALE, 2013; BYBEE, 2010).

Como evidência de mudança, temos o fator sintático, no apontamento da tendência de ordenação pós-verbal para os efetivos pronomes locativos no português contemporâneo. Assim, dos dados do século XVIII para os subsequentes, temos maior variabilidade sintática desses pronomes, com aumento de frequência da ordenação pós-verbal. Como declaramos na seção 2.1, tal resultado corrobora outras evidências desse tipo de ordenação apresentadas em pesquisas sobre a trajetória dos adverbiais em português. Consideramos que a ordenação se constitui, portanto, como um fator estrutural, de natureza gramatical, que tende a se alterar na história da língua nesse uso específico.

De outra parte, os demais fatores revelam traço mais estável. Postulamos que tal estabilidade é devido ao gênero opinativo das fontes pesquisadas, que é correspondente nas três sincronias. Assim, sentido físico virtual, processamento anafórico e frame não-espacial são marcas constitutivas dos pronomes locativos nesses materiais, independentemente da sincronia em questão. Trata-se de traços motivados pela articulação de estratégias de exposição e defesa de pontos de vista, afetadas por (inter) subjetivização e inferências sugeridas, como postulado por Traugott e Dasher (2005).

Os resultados obtidos ensejam, de outra parte, a continuidade da pesquisa. É preciso, por exemplo, verificar se os fatores estáveis aqui referidos, como anaforização e frame nãoespacial, são, na verdade, mais gerais, detectados como tendência em outros gêneros discursivos, o que pode conferir motivação mais gramatical para tais usos. De outra parte, há necessidade de se investigar, na linha da gramaticalização de construções (TRAUGOTT e TROUSDALE, 2013; TRAUGOTT, 2012), como os pronomes locativos se vinculam a outros 

R $\quad \mathbf{E}$
$\mathbf{S}$
T
A
Dossiê - N. 28 - 2014.2 - Mariângela Rios de Oliveira
Monique Petin Kale dos Santos

elementos, na formação de pares mais entrincheirados de sentido e forma, como o daqui vem, tão recorrente no século XVIII.

\section{Referências bibliográficas:}

BARCELLOS, Rodrigo da Costa. Pronomes locativos em textos de dramaturgia: uma análise funcionalista. Dissertação (Mestrado em Letras) - Niterói, RJ, Universidade Federal Fluminense, Instituto de Letras, 2011. 102 fls.

BATORÉO, Hanna. Expressão do espaço no português europeu: contributo psicolinguístico para o estudo da linguagem e cognição. Lisboa: Fundação Calouste Gulbenkian, 2000.

BYBEE, Joan. Language, usage and cognition. Cambridge: Cambridge University Press, 2010.

CAMARA JR. Joaquim Mattoso. Estrutura da língua portuguesa. 28. ed. Petrópolis, RJ: Vozes, 1998.

CASTILHO, Ataliba Teixeira. Nova gramática do português brasileiro. São Paulo: Contexto, 2010.

ERMAN, Britt; WARREN, Beatrice. The idiom principle and the open choice principle. In: Linguistics: an interdisciplinary journal of the language sciences. Berlin; New York: Mouton de Gruyter, n. 2, 2000, p. 29-62.

FILLMORE, Charles. Frame semantics. In: Linguistic Society of Korea (Org.). Linguistics in the morning calm. Seoul: Hanshin, 1982, p. 111-138.

ILARI, Rodolfo et alii. Considerações sobre a posição dos advérbios. In: CASTILHO, Ataliba Teixeira de (Org.). Gramática do português falado: a ordem (Vol. I). São Paulo: Editora da UNICAMP; FAPESP, 1991, p. 63-142.

KOCH, Ingedore Villaça. Desvendando os segredos do texto. São Paulo: Cortez, 2011.

Coesão textual. 2. ed. São Paulo: Contexto, 1990.

MARCUSCHI, Luiz Antônio. Gêneros textuais: definição e funcionalidade. In: DIONÍSIO, Angela; MACHADO, Anna Rachel; BEZERRA, Maria Auxiliadora (Orgs.). Gêneros textuais \& ensino. Rio de Janeiro: Lucerna, 2002, p. 19-36.

MARTELOTTA, Mário. Advérbios: conceito e tendências de ordenação. In: OLIVEIRA, Mariangela Rios; CEZARIO, Maria Maura (Orgs.). Adverbiais: aspectos gramaticais e pressões discursivas. Niterói, RJ: Editora da UFF, 2012, p. 13-96.

. Mudança linguística: uma abordagem baseada no uso. São Paulo: Cortez, 2011. 


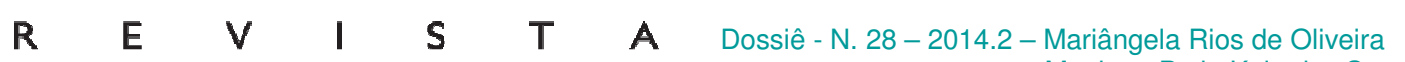

Ordenação dos advérbios qualitativos em _mente no português escrito no Brasil nos séculos XVIII e XIX. Gragoatá, v. 21, 2006, p. 11-26.

; ALONSO, Karen. Funcionalismo, cognitivismo e a dinamicidade da língua. In: SOUZA, Edson Rosa (Org.). Funcionalismo linguístico: novas tendências teóricas (Vol. 1). São Paulo: Contexto, 2012, p. 87-106.

NEVES, Maria Helena. Gramática de usos do português. São Paulo: Editora da UNESP, 2000 .

OLIVEIRA, Mariangela Rios. Tendências atuais da pesquisa funcionalista. In: SOUZA, Edson Rosa (Org.). Funcionalismo linguístico: novas tendências teóricas (Vol. 1). São Paulo: Contexto, 2012, p. 133-152.

; TEIXEIRA, Ana Cláudia Machado. Por uma tipologia funcional dos marcadores discursivos com base no esquema construcional Verbo Locativo. Veredas, Juiz de Fora, MG, UFJF, v. 16, 2012, p. 19-35.

; SANTOS, Leonardo. Padrões de uso da expressão 'sei lá' no português. Signótica, Goiânia, UFG, v. 23, 2011, p. 363-384.

; BARCELLOS, Rodrigo da Costa. Padrões de uso do locativo 'aí' no português escrito do século XVIII ao XX. Revista do GELNE, Fortaleza, UFC, v. 13, 2011, p. 173-196.

Pronomes locativos na dramaturgia dos séculos XVIII e XIX em língua portuguesa. In: OLIVEIRA, Mariangela Rios; CEZARIO, Maria Maura (Org.). Adverbiais: aspectos gramaticais e pressões discursivas. Niterói, RJ: Editora da UFF, 2012, p. 119-138.

; ROCHA, Rossana Alves. As expressões "daqui vem” e "daí vem” como instanciações da construção LOC + SV no português contemporâneo. Caligrama, Minas Gerais, UFMG, v. 16, 2011, p. 155-176.

PAIVA, Maria da Conceição. Proformas adverbiais e encadeamento dêitico. In: RONCARATI, Cláudia; ABRAÇADO, Jussara (Orgs.). Português brasileiro: contato linguístico, heterogeneidade e história. Rio de Janeiro: Faperj; 7Letras, 2003, p. 132-143.

TRAUGOTT, Elizabeth. Toward a coherent account of grammatical constructionalization. In: SMIRNOVA, E; BARODAL, J; SOMMERER, L (Eds.). Historical construction grammar, 2012. p. 1-21.

; TROUSDALE, Graeme. Constructionalization and constructional changes. Oxford: Oxford University Press, 2013.

; DASHER, Richard. Regularity in semantic change. Cambridge: Cambridge University Press, 2005.

TRAVAGLIA, Luiz Carlos. Gramática e interação: uma proposta para o ensino de gramática no $1^{\circ}$ e $2^{\circ}$ graus. São Paulo: Cortez, 1997. 


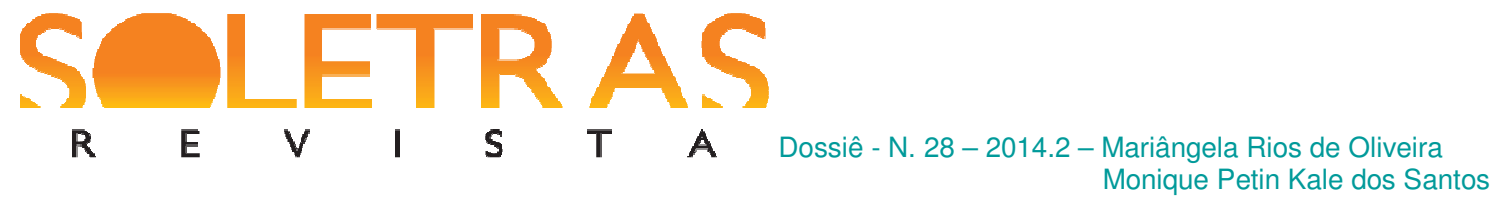

VALADARES, Thiago Quintas. Pronomes locativos em cartas pessoais: relações entre discurso e gramática. Dissertação (Mestrado em Estudos de Linguagem) - Niterói, RJ, Universidade Federal Fluminense, Instituto de Letras, 2012. 103 fls.

\title{
Trends in the usage of locative pronouns in Portuguese language from the XVIIIth to the XIXth centuries
}

\begin{abstract}
Analysis of locative pronouns in the Portuguese language texts from the eighteenth to the twentieth centuries. Based on Usage-based linguistic model (TRAUGOTT and TROUSDALE, 2013; BYBEE, 2010), among other, we investigate the usage tendency of the locative pronouns aí, ali, aqui, cá and lá, as well as their agglutinated daí, dali and daqui, based on four factors - syntatic, semantic, textual and cognitive. These factors indicate linguistic change, with the change in the ordering of the locative, pre to post-verbal surveyed over the centuries, and, on the other hand, these factors show stability in use also linked to the discursive context of opinion researched sources.
\end{abstract}

Key words: Locative pronouns. Funcionalism. Portuguese language. Order. Historical Linguistics.

Recebido em: 19 de dezembro de 2014.

Aprovado em: 09 de janeiro de 2015. 